\title{
Correlation of Clinical and Radiological Outcome After Anterior Cervical Discectomy and Fusion With a Polyetheretherketone Cage
}

\author{
Savvas L. Spanos ${ }^{\mathrm{a}, \mathrm{b}, \mathrm{h}}$, Ioannis D. Siasios ${ }^{\mathrm{c}, \mathrm{d} \text {, e }}$, Vassilios G. Dimopoulos ${ }^{\mathrm{c}, \mathrm{d}}$, \\ Konstantinos N. Paterakis ${ }^{\mathrm{a}}$, Dimos S. Mastrogiannis ${ }^{\mathrm{f}}$, Theofanis P. Giannis ${ }^{\mathrm{g}}$, \\ Aggeliki A. Fotiadou ${ }^{a}$, John Pollina ${ }^{\text {c, d }}$, Kostas N. Fountas ${ }^{\text {a, g }}$
}

\begin{abstract}
Background: Anterior cervical discectomy and fusion (ACDF) with a polyetheretherketone (PEEK) cage is considered as the gold standard for patients with cervical disc disease. However, there are limited in vivo data on the impact of ACDF on the cervical kinematics and its association with patient-reported clinical outcomes. The purpose of this study was to investigate the impact of altered cervical sagittal alignment (cervical lordosis) and sagittal range of motion (ROM) on patients' self-reported pain and functional disability, after ACDF with a PEEK cage.
\end{abstract}

Methods: We prospectively studied 74 patients, who underwent single-, or consecutive two-level ACDF with a PEEK interbody cage. The clinical outcomes were assessed by using the pain numeric rating scale (NRS) and the neck disability index (NDI). Radiological outcomes included cervical lordosis and C2-C7 sagittal ROM. The outcome measures were collected preoperatively, at the day of patients' hospital discharge, and also at 6 and 12 months postoperatively.

Results: There was a statistically significant reduction of the NRS and NDI scores postoperatively at each time point $(\mathrm{P}<0.005)$. Cervical lordosis and also ROM significantly reduced until the last followup $(\mathrm{P}<0.005)$. There was significant positive correlation between

Manuscript submitted December 16, 2017, accepted January 8, 2018

aDepartment of Neurosurgery, School of Medicine, University of Thessaly, Larissa, Greece

bepartment of Physiotherapy, School of Health and Welfare, Technological Education Institute of Sterea Ellada, Lamia, Greece

'Department of Neurosurgery, Jacobs School of Medicine and Biomedical Sciences, University at Buffalo, State University of New York, Buffalo, NY, USA

${ }^{\mathrm{d} D e p a r t m e n t}$ of Neurosurgery, Kaleida Health, Buffalo, NY, USA

eDepartment of Neurosurgery, Papageorgiou Hospital, Thessaloniki, Greece

fDepartment of Nursing, School of Health and Welfare, Technological Education Institute of Sterea Ellada, Lamia, Greece

gDepartment of Neurosurgery, University Hospital of Larissa, Larissa, Greece

${ }^{\mathrm{h}}$ Corresponding Author: Savvas Spanos, Department of Physiotherapy, Technological Education Institute of Sterea Ellada, 3rd km Old National Road Lamia-Athens, Lamia 35100, Greece. Email: sspanos64@gmail.com

doi: https://doi.org/10.14740/jocmr3326w
NRS and NDI preoperatively, as well as at 6 and 12 months postoperatively $(\mathrm{P}<0.005)$. In regard to the ROM and the NDI scores, there was no correlation preoperatively $(\mathrm{P}=0.199)$ or postoperatively $(6$ months, $\mathrm{P}=0.322 ; 12$ months, $\mathrm{P}=0.476)$. Additionally, there was no preoperative $(\mathrm{P}=0.134)$ or postoperative $(6$ months, $\mathrm{P}=0.772 ; 12$ months, $\mathrm{P}=0.335$ ) correlation between the NDI scores and cervical lordosis.

Conclusions: In our study, reduction of cervical lordosis and sagittal ROM did not appear to significantly influence on patients' self-reported disability. Such findings further highlight the greater role of pain level over the mechanical limitations of ACDF with a PEEK cage on patients' own perceived recovery.

Keywords: Anterior cervical discectomy and fusion; Cervical ROM; Neck disability index; Numeric rating scale; Pain; PEEK cage; Cervical lordosis

\section{Introduction}

Anterior cervical discectomy with fusion (ACDF) constitutes one of the most commonly performed procedures in spine surgery, characterized by quite high success and low complication rates. ACDF is regarded as the standard surgical treatment option for cervical spondylosis with myelopathy, radiculopathy and/or symptomatic disc herniation, when conservative management has failed. The reported results for ACDFs are excellent for the patients, as this is generally stated in the pertinent literature $[1,2]$. ACDF in the vast majority of cases successfully reduces neck and arm pain, restores both vertebral disc height and foraminal height, and also leads to an osseous fusion $[3,4]$.

ACDF using a polyetheretherketone (PEEK) cage is considered by many spinal surgeons, as the gold standard for patients with cervical disc herniation. PEEK is biocompatible, radiolucent, and has a modulus of elasticity similar to that of the bone. PEEK cages may achieve a significant increase in the disc space height and the neural foramina, contributing to nerve root decompression and, thereby, further controlling pain. In addition, the implantation of a PEEK cage is char- 
Table 1. Evaluation Plan

\begin{tabular}{llllc}
\hline Evaluation method & Preoperative & $\begin{array}{l}\text { Postoperative } \\
\text { (day of hospital discharge) }\end{array}$ & 6-month follow-up & 12-month follow-up \\
\hline Lateral radiographs in neutral position & $\sqrt{ }$ & $\sqrt{ }$ & $\sqrt{ }$ & $\sqrt{ }$ \\
Full flexion/extension lateral radiographs & $\sqrt{ }$ & & $\sqrt{ }$ & $\sqrt{ }$ \\
Cervical lordosis estimation (Cobb angle) & $\sqrt{ }$ & $\sqrt{ }$ & $\sqrt{ }$ & $\sqrt{ }$ \\
Cervical ROM calculation & $\sqrt{ }$ & $\sqrt{ }$ & $\sqrt{ }$ & $\sqrt{ }$ \\
NRS & $\sqrt{ }$ & & $\sqrt{ }$ & $\sqrt{ }$ \\
NDI & $\sqrt{ }$ & & \\
\hline
\end{tabular}

acterized by a significantly lower infection rate, compared to ACDF with an autologous bone graft $[5,6]$.

On the other hand, partial fusion of the cervical spine inevitably resulted in alternations to the physiological biomechanics of the area [7]. Inadequate cervical lordosis and reduced cervical range of motion (ROM) have been suggested to be significant negative contributors in the outcome of ACDF surgery [8].

Although there are several clinical and radiological studies in the literature regarding the progress of fusion, as well as the clinical improvement of patients undergoing ACDF with a PEEK cage, there are a limited number of studies, investigating the correlation of clinical improvement with cervical lordosis, and also with cervical ROM of such patients.

The purpose of our current study was to investigate the impact of altered cervical sagittal alignment (cervical lordosis) as well as the impact of cervical sagittal ROM changes, on patients' self-reported pain and functional disability, in patients undergoing ACDF with a PEEK cage.

\section{Materials and Methods}

This was a prospective, same subjects, repeated-measures study.

\section{Study group}

The study group exclusively consisted of patients that fully completed the research protocol (6 and 12 months follow-ups). Therefore we analyzed the clinical and radiological outcomes of 74 patients, who underwent single-, or consecutive twolevel ACDF using a PEEK interbody cage filled with allograft. All participants suffered cervical radiculopathy or myelopathy, which had remained unresponsive to any conservative treatment, for at least a 3-month period. The eligibility of the patients was assessed and determined by the same neurosurgeon. Demographic variables such as age, sex, and smoking habits were recorded. Radiological and clinical evaluation of the patients was preoperatively performed, at the day of their hospital discharge, and then at 6 and 12 months postoperatively. A signed informed consent was obtained from all participants before their enrolment in the study. The study protocol was conducted in agreement with the Declaration of Helsinki and approved by the scientific council of our hospital.

\section{Assessment of outcome}

\section{Clinical evaluation}

Intraoperative and postoperative complications were noted. Numeric rating scale (NRS) and the neck disability index (NDI) were used in order to obtain a time series of self-reported neck/arm pain severity and cervical spine function changes. NRS and NDI are two of the most commonly cited instruments for assessing self-rated pain and disability in patients with neck pain [9]. The above clinical outcome instruments were administered by the single blinded research assistant and without the presence of the treating surgeon.

\section{Radiologic evaluation}

The radiologic evaluation of the cervical spine in the pre- and postoperative period included lateral radiographs in neutral, and also in full active flexion-extension, in order to obtain a time series of cervical lordosis and sagittal ROM changes. On the basis of the radiographic images, we calculated the cervical lordosis in neutral and sagittal ROM of $\mathrm{C} 2-\mathrm{C} 7$, using the Cobb method. The Cobb angle was determined as the angle of intersection of two tangential lines drawn along the inferior end plate of the $\mathrm{C} 2$ and the inferior end plate of the C7. Lordosis was expressed as a positive value and kyphosis was expressed as a negative value so as sagittal ROM was determined by measuring the difference in alignment between maximum flexion and extension. Radiographic measurement data were collected from an independent observer, who was not involved in the management of these patients. Representations of the clinical and radiologic evaluation are illustrated in Table 1.

\section{Statistical analysis}

The collected data were processed using the Statistical Package for the Social Sciences software (SPSS version 20, IBM Corporation, NY, USA). All results are presented as the mean value $\pm \mathrm{SD}$. The Friedman's two-way analysis of variance methodology for non-parametric data, and the repeated measures ANOVA methodology as well as the paired samples $t$-test methodology for parametric data, were carried out to assess 
Table 2. Summary of Inclusion and Exclusion Criteria

\author{
Inclusion criteria \\ Adult patients (age $\geq 18$ ) \\ and filling out of necessary paperwork \\ Conservative treatment failed for at least 3 months (for only pain-related pathology) \\ Exclusion criteria \\ Previous cervical operations/cervical spine tumors/infections of the cervical spine/cervical injuries \\ Mental abnormalities
}

Symptomatic single- or two-level disc disease between C3 and C7/neck or arm pain (radicular) and/or a functional/neurological deficit/ at least one of the following conditions confirmed by CT or MRI: herniated nucleus pulposus, spondylosis, and/or loss of disc height

Mentally, psychologically, and physically able to comply this protocol, including adherence to follow-up schedules and requirements,

the effect of ACDF on time-related changes (preoperative, postoperative, 6, and 12 months) in cervical lordosis, sagittal ROM, pain NRS and NDI. Pearson product moment correlation coefficient methodology for parametric data and the Spearman rank order correlation coefficient methodology for non-parametric data were also used to determine the relationship between NDI and, NRS, cervical lordosis and sagittal ROM, respectively. Additionally, the statistical significance of the observed differences of the mean between subgroups was calculated by using the independent samples $t$-test methodology. A $\mathrm{P}$ value of $<0.05$ was considered to be significant in all the above statistical tests.

\section{Results}

\section{Patient demographics and surgical data}

Using the inclusion/exclusion criteria presented in Table 2, 74 patients (36 males and 38 females; mean age $50.09 \pm 13.54$ years) with cervical radiculopathy or myelopathy, were enrolled. There was a minimum $(<20 \mathrm{~mL})$ blood loss in $37(49.3 \%)$ patients, and a mean of $75.66 \pm 31.56 \mathrm{~mL}$ in the remaining 38 $(50.7 \%)$ patients. Sixty-five patients $(86.7 \%)$ used only hard cervical collar postoperatively, while the other $10(13.3 \%)$ used hard and soft collar, sequentially. A summary of the demographics and the surgical details are presented in Table 3.

\section{Complications}

In one patient $(1.35 \%)$ an accidental intraoperative esophageal perforation occurred, and a surgical repair of the iatrogenic esophageal tear was performed at a different surgical setting, by a cardiothoracic surgeon. The patient stayed with no oral intake and parenteral alimentation for 6 days after his second surgery, and recovered with no further consequences. His follow-up revealed no dysphagia or any other esophageal motility difficulties. Two patients $(2.7 \%)$ developed postoperatively a clinically evident soft tissue hematoma, which was conservatively managed with close observation, requiring no surgical evacuation. These two patients recovered with no further con- sequences. Additionally, three patients (4.05\%) experienced postoperatively mild to moderate dysphagia, with one of them simultaneously presenting mild hoarseness. Their symptoms slowly improved within the first 2 - 4 postoperative weeks, and they completely resolved with no further disturbances. The cumulative complication rate in our current series was $8.1 \%$ per patient, and $7.31 \%$ per surgical level.

\section{Clinical outcome}

Neck/arm NRS scores and NDI scores were available from

Table 3. Summary of Patients' Demographic Characteristics, and Surgical Data

\begin{tabular}{|ll}
\hline Characteristic & No. of patients/value (\%) \\
\hline No. of patients & 74 \\
Male/female ratio & $36: 38$ \\
Age (years) & \\
$\quad$ Mean & $50.09 \pm 13.54$ \\
$\quad$ Range & $28-86$ \\
\hline Body mass index (BMI) & \\
$\quad$ Mean & $27.82 \pm 4.73$ \\
$\quad$ Range & $20.3-42.0$ \\
\hline No. of smokers & $37(50)$ \\
Radiculopathy/myelopathy ratio & $36: 38$ \\
\hline Single-level ACDF & $66(89.19)$ \\
Two-level ACDF & $8(10.81)$ \\
ACDF (disc level) & \\
\hline C3-4 & $14(17.07)$ \\
C4-5 & $16(19.51)$ \\
C5-6 & $38(46.34)$ \\
C6-7 & $14(17.07)$ \\
\hline Duration of postoperative brace (days) & $34.44 \pm 17.56$ \\
\hline Mean & $30-120$ \\
\hline Range &
\end{tabular}


Table 4. Outcomes of Clinical Parameters for Subgroups (Mean \pm SD) and the Significance of the Differences Between Subgroups

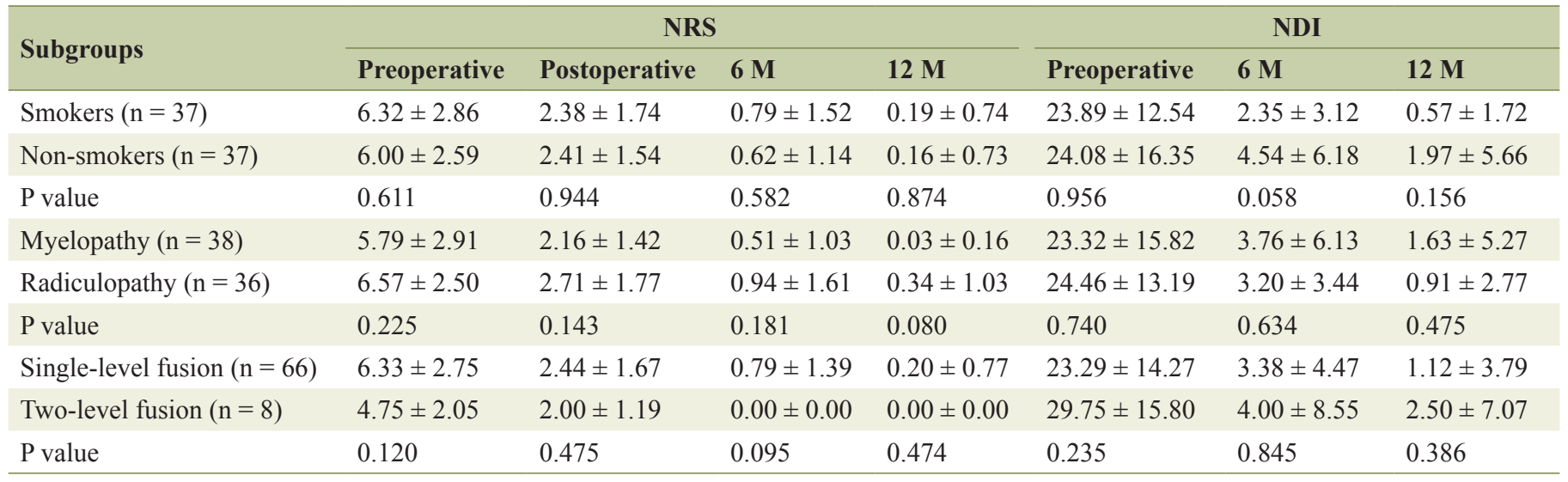

$\mathrm{M}$ indicates months. NDI (\%).

all participants. The difference of the observed mean between subgroups (smokers/non-smokers, myelopathy/radiculopathy, single-level fusion/two-level fusion) was statistically insignificant for any of the explored clinical parameters (Table 4). Therefore, we calculated the sample $(n=74)$ as homogeneous.

The observed mean NRS score immediately after surgery demonstrated a significant reduction from the preoperative one $(\mathrm{P}=0.000)$. This reduction was maintained significant at 6 months $(\mathrm{P}=0.000)$ and 12 months postoperatively $(\mathrm{P}=0.000)$. Moreover, the calculated mean NDI score at the 6-month evaluation showed statistically significant reduction from the preoperative one $(\mathrm{P}=0.000)$ and this reduction was maintained significant at the 12-month follow-up evaluation $(\mathrm{P}=0.000)$. The changes of the clinical outcomes over time are illustrated in Figure 1 and are summarized in Table 5. Additionally, there was significant positive correlation between NRS and NDI preoperatively $(\mathrm{r}=0.351, \mathrm{P}=0.001)$, at the 6 -month follow-up evaluation $(\mathrm{r}=0.241, \mathrm{P}=0.004)$, as well as at the 12-month follow-up evaluation $(\mathrm{r}=0.250, \mathrm{P}=0.003)$.

\section{Radiological outcome}

There was a successful implantation of a PEEK cage in all participants, with no mechanical failures or other implant associated malfunctions. Additionally, there was a successful fusion in all participants, with no pseudoarthrosis at the implantation levels until the last follow-up (12 months). The difference of the observed mean between subgroups was statistically insignificant for any of the explored radiologic parameters (Table $6)$. Therefore, we calculated the sample $(n=74)$ as homogeneous, too. A summary of the radiological results is presented in Table 5.

\section{Cervical lordosis}

The mean postoperative Cobb angle from the $\mathrm{C} 2$ to the $\mathrm{C} 7$ in neutral (index of the cervical lordosis) was found to be slightly increased compared to the preoperative one. However, this difference was statistically insignificant $(\mathrm{P}=0.429)$. Interestingly, the mean Cobb angle at 6 months postoperatively was lower than the respective preoperative one. However, this difference was statistically insignificant $(P=0.0095)$ (a $P$ value of $<0.0083$ was considered to be significant due to Bonferroni correction). At the 12-month postoperative evaluation, the mean Cobb angle was again lower than the preoperative one, and this difference reached the levels of statistical significance $(\mathrm{P}=0.008)$. Additionally, there was no significant correlation between the NDI scores and the Cobb angle preoperatively ( $\mathrm{r}$ $=0.175, \mathrm{P}=0.134)$, at 6 months postoperatively $(\mathrm{r}=0.034, \mathrm{P}$ $=0.772)$, and also at 12 months $(\mathrm{r}=-0.113, \mathrm{P}=0.335)$ postoperatively.

\section{C2-C7 sagittal ROM}

The 6-month follow-up mean sagittal ROM was significantly reduced compared to the preoperative one $(\mathrm{P}=0.000)$ and the observed difference remained significant $(\mathrm{P}=0.000)$ at the 12-month follow-up evaluation. Further processing of our data demonstrated that this reduction of the ROM was more prominent in patients undergoing two-level ACDF than those undergoing single-level ACDF (Fig. 2, Table 6). Additionally, in regard to the calculated ROM and NDI scores, there was no correlation preoperatively $(\mathrm{r}=0.099, \mathrm{P}=0.199)$, at 6 months $(\mathrm{r}=0.056, \mathrm{P}=0.322)$ and also at 12 months $(\mathrm{r}=-0.007, \mathrm{P}=$ $0.476)$ postoperatively.

\section{Discussion}

To our knowledge, there is limited number of studies to evaluate the association of cervical lordosis and ROM with patient-reported functional disability. Contrary to the generally accepted clinical deduction, the results of the current study indicated that cervical lordosis and ROM do not exert a significant impact on patient-reported functional capacity. On the other hand, our results indicated that pain level exerts a significant impact on patient-reported functional capacity. 

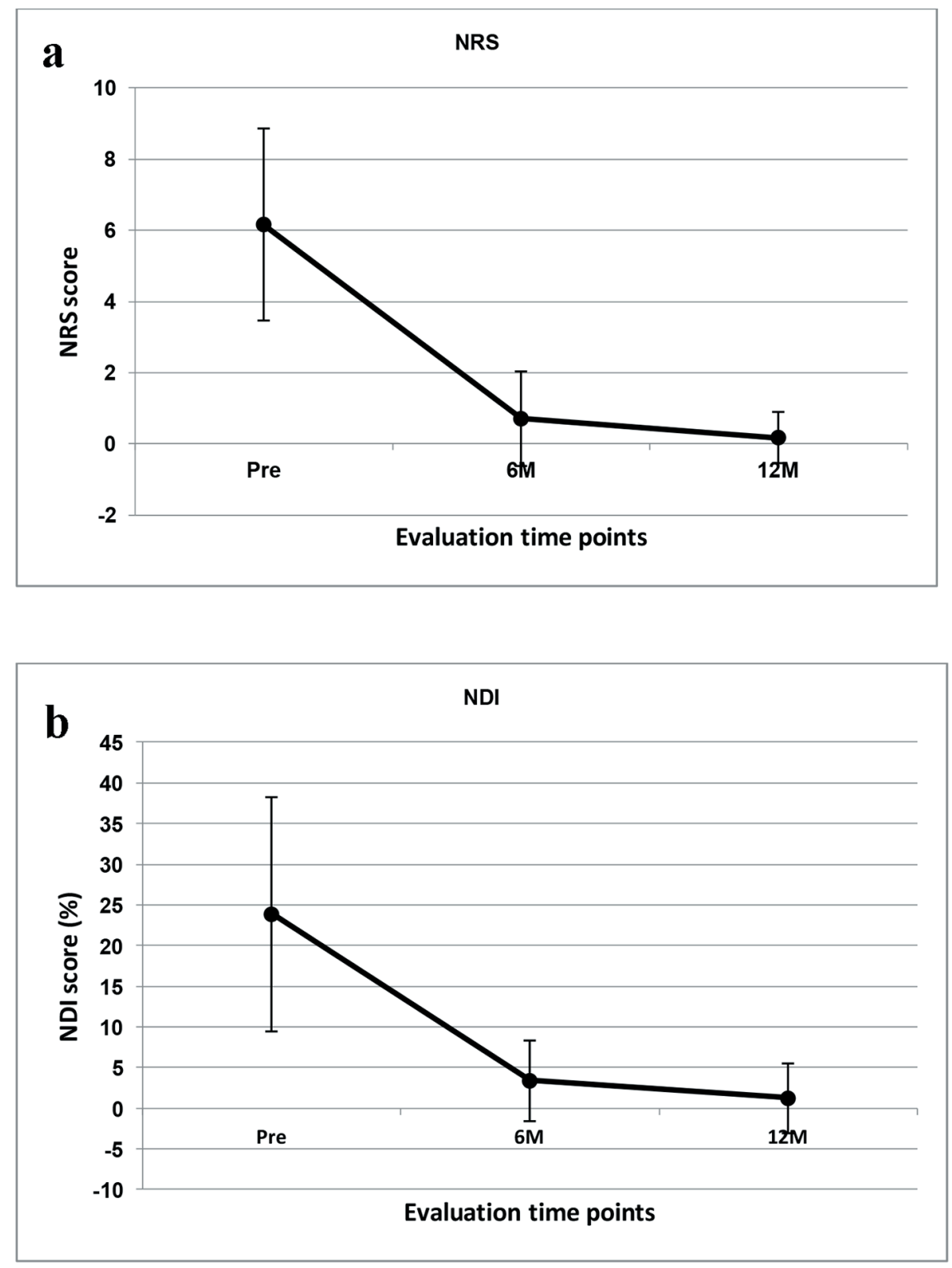

Figure 1. Line graphs illustrating: (a) the pain NRS mean scores and (b) the NDI mean scores preoperatively and then at 6- and 12-month time points. There was significant difference between time points for both instruments.

The essential purpose of ACDF with a PEEK cage is to decompress the spinal cord and other neural structures whilst to maintain the stability of the cervical spine. Additionally, there is strong body of evidence that PEEK cage implantation restores and successfully maintains the intervertebral disc height and also the neural foramina height, postoperatively $[4,10-$ 12]. Therefore, the achieved mechanical decompression of the compressed cervical roots and the possible restoration of the local micro-circulation may result in pain reduction [13]. Consistent with other clinical series [4, 10, 11, 14-16], our current data clearly indicated that there was a statistically significant reduction of neck/arm pain among our patients at their discharge from the hospital. This effect was maintained during their 12-month follow-up period.
In accordance to other clinical series with similar samples and follow-up periods [17-19], our data demonstrated that there was statistically significant postoperative improvement of the NDI score. It has been postulated that the postoperative pain reduction is strongly associated with the patient's satisfaction $[14,20]$. Additionally, it is well known that NDI was designed to measure disability in activities of daily living due to neck pain $[21,22]$. The above would be an explanation of our findings regarding the parallel significant reduction in neck/arm pain mean scores and NDI mean scores (Table 5, Fig. 1). There are several studies supporting the concept that NDI reduction is associated to pain reduction through the postoperative pe$\operatorname{riod}[10,16,23-25]$ and our study results strongly support this. More specifically, there was statistically significant correlation 
Table 5. Outcomes of Clinical and Radiological Parameters for the Sample as a Whole (Mean \pm SD)

\begin{tabular}{lllll}
\hline Outcome & Preoperative & Postoperative & 6 M & 12 M \\
\hline NRS $(n=74)$ & $6.16 \pm 2.7(0-10)$ & $2.40 \pm 1.62(0-6)$ & $0.70 \pm 1.33(0-6)$ & $0.17 \pm 0.72(0-4)$ \\
NDI $(\mathrm{n}=74)$ & $23.88 \pm 14.4(0-74)$ & & $3.40 \pm 4.96(0-25)$ & $1.25 \pm 4.29(0-25)$ \\
Cobb angle $(\mathrm{n}=74)$ & $14.7 \pm 9.36(-22.0-42.0)$ & $14.88 \pm 8.36(2.0-43.0)$ & $12.0 \pm 9.56(-9.0-46.0)$ & $11.96 \pm 9.55(-9.0-46.0)$ \\
ROM $(\mathrm{n}=74)$ & $50.8 \pm 12.59(15.0-68.0)$ & & $41.25 \pm 12.24(12.0-63.5)$ & $41.22 \pm 11.82(12.0-60.0)$ \\
\hline
\end{tabular}

M indicates months. NDI (\%). Cobb angle and ROM $\left({ }^{\circ}\right)$. Min-max in brackets.

Table 6. Outcomes of Radiological Parameters for Subgroups (Mean \pm SD) and the Significance of the Differences Between Subgroups

\begin{tabular}{|c|c|c|c|c|c|c|c|}
\hline \multirow{2}{*}{ Subgroups } & \multicolumn{4}{|c|}{ Cobb angle } & \multicolumn{3}{|c|}{ ROM } \\
\hline & Preoperative & Postoperative & $6 \mathrm{M}$ & $12 \mathrm{M}$ & Preoperative & $6 \mathrm{M}$ & $12 \mathrm{M}$ \\
\hline Smokers $(n=37)$ & $14.95 \pm 11.26$ & $16.40 \pm 8.74$ & $11.40 \pm 10.33$ & $11.39 \pm 10.29$ & $51.45 \pm 11.04$ & $42.54 \pm 10.91$ & $42.80 \pm 10.42$ \\
\hline$P$ value & 0.637 & 0.085 & 0.780 & 0.804 & 0.320 & 0.386 & 0.269 \\
\hline Myelopathy $(\mathrm{n}=38)$ & $16.80 \pm 7.89$ & $15.55 \pm 8.72$ & $12.62 \pm 8.61$ & $12.58 \pm 8.60$ & $52.37 \pm 10.93$ & $42.26 \pm 12.20$ & $42.19 \pm 11.32$ \\
\hline $\mathrm{P}$ value & 0.079 & 0.238 & 0.360 & 0.354 & 0.069 & 0.390 & 0.387 \\
\hline Single-level fusion $(\mathrm{n}=66)$ & $13.86 \pm 9.10$ & $14.39 \pm 7.36$ & $11.26 \pm 8.70$ & $11.21 \pm 8.65$ & $49.88 \pm 12.68$ & $41.62 \pm 12.49$ & $41.50 \pm 12.06$ \\
\hline Two-level fusion $(\mathrm{n}=8)$ & $19.19 \pm 8.62$ & $15.87 \pm 12.45$ & $15.44 \pm 13.35$ & $15.37 \pm 13.41$ & $50.69 \pm 13.14$ & $37.93 \pm 9.79$ & $38.64 \pm 9.79$ \\
\hline$P$ value & 0.121 & 0.622 & 0.232 & 0.232 & 0.867 & 0.453 & 0.548 \\
\hline
\end{tabular}

$\mathrm{M}$ indicates months. Cobb angle and ROM $\left({ }^{\circ}\right)$.

between these variables (NDI and NRS) in the preoperatively obtained scores as well as in the postoperatively obtained scores (6- and 12-month).

It is well known that lordotic sagittal alignment of the cervical spine is absolutely necessary, in order the spine to sustain the mechanical stresses of daily-living activities. McAviney et al [26] reported statistically significant correlation between neck pain and cervical lordosis less than $20^{\circ}$. Additionally, according to $\mathrm{Wu}$ et al [27], the restoration or the maintenance of acceptable cervical lordosis after ACDF affects the long-term

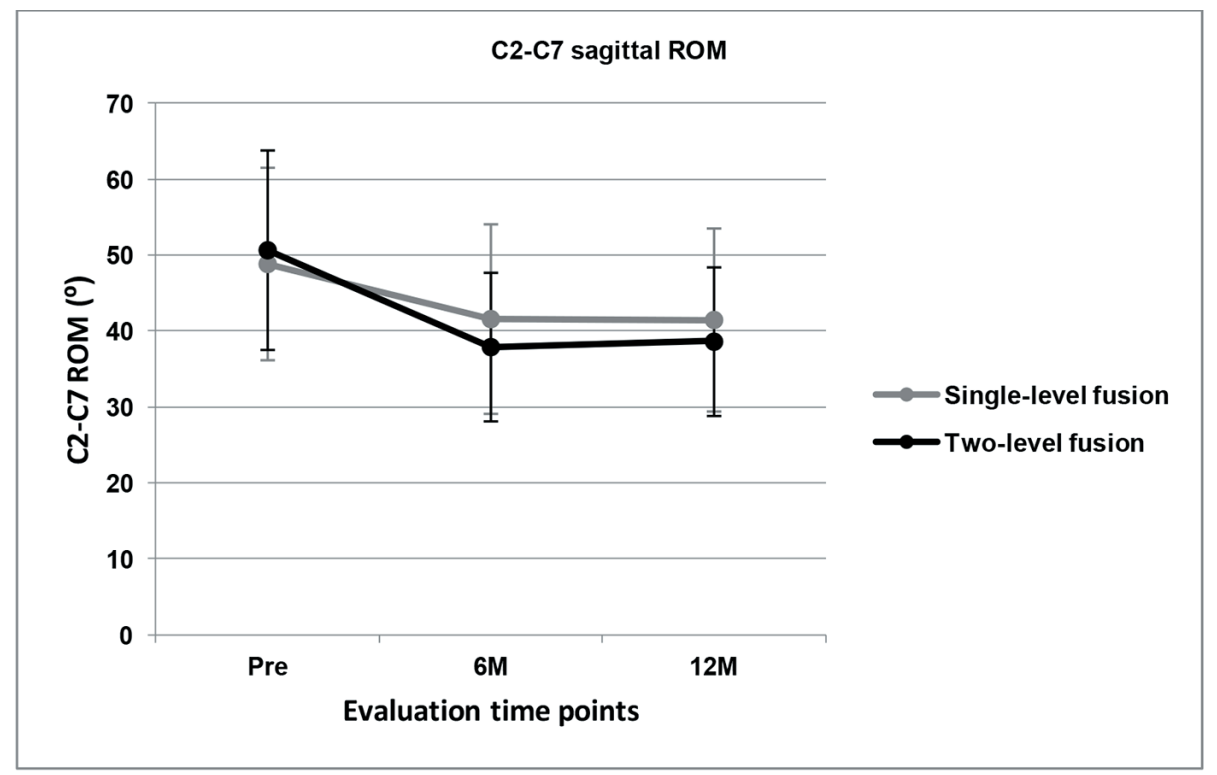

Figure 2. Line graphs illustrating C2-C7 ROM for the single- and two-level ACDF groups preoperatively and then at 6- and 12 -month time points. There was significant difference between time points for both conditions. 
clinical outcome. Decreased cervical lordotic angle seems to be associated with earlier adjacent degenerative changes [28]. There are several studies in the literature examining the effect of ACDF with a PEEK cage in the management of cervical lordosis. They resulted in significant lordosis restoration postoperatively that was maintained throughout the final followup (12 - 24 months) [16-19]. Contrariwise, our results showed that there was a slight increase of the mean Cobb angle in neutral immediately after surgery, which however was lost during the 12-month follow-up period (Table 5). Unfortunately, we cannot identify any factors for explaining these findings in our series. An explanation for this would be the possible adjacent level degeneration $[28,29]$, a factor that we did not explore. Nevertheless, our current Cobb angle measurements are into acceptable limits, since the reported in the pertinent literature predictable lordotic angle values are $13.90 \pm 12.30^{\circ}$ for healthy subjects, while $11.40 \pm 9.80^{\circ}$ for myelopathic patients [30].

In agreement with previous studies $[31,32]$, patients underwent ACDF in the current study demonstrated a statistically significant reduction of the C2-C7 sagittal ROM postoperatively (6-months follow-up) which remained reduced at the 12-month follow-up evaluation (Table 5). This reduction was more prominent among patients undergoing two-level ACDF (Fig. 2, Table 6). This is in contrast with previous findings, which have reported a significant improvement in ROM following ACDF, even in those with multilevel fusions [14, $33,34]$. According to Chien et al [31], one plausible explanation for the discrepancies may lie with the differences in the method of how the ROM was obtained. Results presented in our study were based on radiographs measured through C2C7, where the other studies have utilized external wearable devices such as a helmet with goniometers or inclinometers to obtain the global ROM. Such devices commonly include the ROM contributed from the upper cervical and cranial junction [31]. Another plausible explanation is that in the patients who underwent ACDF for radiculopathy, a pathological condition in which the pain cause reduced ROM, decreased radicular pain postoperatively results into improved postoperative ROM. Finally, on the basis of the results of the current study and known in vitro data, ACDF with a PEEK cage is likely to be associated with a reduction of sagittal ROM, which is potentially correlated with the number of fused levels [31].

A cumulative interpretation of our data indicates that our patients had improved self-reported pain intensity (NRS) and disability (NDI) profile, maintained their C2-C7 lordosis at predictable values, while they had reduced sagittal cervical ROM. Similarly, Seng et al [32] documented postoperative reduction of patient-reported pain intensity and disability, along with sagittal cervical ROM reduction. It has been previously stated that there is a relation between cervical ROM, pain and finally, disability [33]. Moreover, it has been postulated that postoperative restoration of the cervical lordosis influences the overall, long-term, clinical outcome. Based on these hypotheses, the observed improvement of patient-reported disability (NDI) in our current study should be accompanied by a restored cervical lordosis postoperatively, as well as by an increased, or at least unchanged, sagittal cervical ROM. However, in contrast to the observed positive association between patient-reported functional disability and calculated cervical lordosis and ROM in conservatively managed patients [35], our results, in accordance to other studies [33], indicated that in ACDF patients, pain levels are more strongly associated with the reported disability levels than the reduction of cervical lordosis as well as the loss of ROM. Chien et al [31] may provide an explanation for our findings, since they claim that patients tend to use their perceived pain levels instead of available ROM when attempting to determine their own functional disability levels. Therefore, such finding highlights the importance of adequate pain management postoperatively. On the other hand, pain-aggravating physical therapy techniques aiming to improve ROM may have an opponent effect on patientperceived functional disability and should be better respected by clinicians at postoperative periods.

\section{Limitations}

One notable limitation of our study involves the possibility of deficiencies in our method of measuring cervical ROM. Cervical movement is multidirectional, but in our study, radiographic analysis of ROM in only one plane was calculated. Multidirectional movements, including rotational motion and lateral bending, were not considered.

\section{Conclusions}

Despite the inherent limitations, this study extends our current knowledge base on how changes on pain intensity and also kinematical changes after ACDF influence on patient-reported outcomes. Our results suggest that the employment of ACDF with a PEEK cage successfully reduced the preoperative neck/ radicular pain, as well as the patient's preoperative associated disability. At the same time, it reduced cervical lordosis (however at predictable values), and decreased the sagittal cervical ROM postoperatively. Nevertheless, reduction of cervical lordosis and sagittal ROM did not appear to significantly influence on patients' self-reported disability. Finally, such findings further highlight the greater role of pain level over the mechanical limitations of ACDF with a PEEK cage on patients' own perceived recovery.

\section{Competing Interests}

The authors declare that they have no competing interests.

\section{Grant Support}

None.

\section{Financial Disclosure}

None. 


\section{References}

1. Schroeder GD, Kurd MF, Millhouse PW, Vaccaro AR, Hilibrand AS. Performing an anterior cervical discectomy and fusion. Clin Spine Surg. 2016;29(5):186-190.

2. Fountas KN, Kapsalaki EZ, Nikolakakos LG, Smisson HF, Johnston KW, Grigorian AA, Lee GP, et al. Anterior cervical discectomy and fusion associated complications. Spine (Phila Pa 1976). 2007;32(21):2310-2317.

3. Xie JC, Hurlbert RJ. Discectomy versus discectomy with fusion versus discectomy with fusion and instrumentation: a prospective randomized study. Neurosurgery. 2007;61(1):107-116; discussion 116-107.

4. Gok H, Onen MR, Yildirim H, Gulec I, Naderi S. Empty bladed PEEK cage for interbody fusion after anterior cervical discectomy. Turk Neurosurg. 2016;26(1):105-110.

5. Park HW, Lee JK, Moon SJ, Seo SK, Lee JH, Kim SH. The efficacy of the synthetic interbody cage and Grafton for anterior cervical fusion. Spine (Phila Pa 1976). 2009;34(17):E591-595.

6. Landriel FA, Hem S, Goldschmidt E, Ajler P, Vecchi E, Carrizo A. Polyetheretherketone interbody cages versus autogenous iliac crest bone grafts with anterior fixation for cervical disc disease. J Spinal Disord Tech. 2013;26(2):61-67.

7. Nunley PD, Jawahar A, Kerr EJ, 3rd, Gordon CJ, Cavanaugh DA, Birdsong EM, Stocks M, et al. Factors affecting the incidence of symptomatic adjacent-level disease in cervical spine after total disc arthroplasty: 2to 4-year follow-up of 3 prospective randomized trials. Spine (Phila Pa 1976). 2012;37(6):445-451.

8. Miyazaki M, Hymanson HJ, Morishita Y, He W, Zhang $\mathrm{H}$, Wu G, Kong MH, et al. Kinematic analysis of the relationship between sagittal alignment and disc degeneration in the cervical spine. Spine (Phila Pa 1976). 2008;33(23):E870-876.

9. Cleland JA, Fritz JM, Whitman JM, Palmer JA. The reliability and construct validity of the Neck Disability Index and patient specific functional scale in patients with cervical radiculopathy. Spine (Phila Pa 1976). 2006;31(5):598602.

10. Park JH, Roh SW. Anterior cervical interbody fusion using polyetheretherketone cage filled with autologous and synthetic bone graft substrates for cervical spondylosis: comparative analysis between PolyBone(R) and iliac bone. Neurol Med Chir (Tokyo). 2013;53(2):85-90.

11. Guven M, Cosar M, Alkan B, Aras AB, Akman T, Safak $\mathrm{O}$, Karaarslan O, et al. Comparison of anterior cervical discectomy fusion techniques: bladed and non bladed PEEK cages. Turk Neurosurg. 2016;26(3):404-410.

12. Toth JM, Wang M, Estes BT, Scifert JL, Seim HB, 3rd, Turner AS. Polyetheretherketone as a biomaterial for spinal applications. Biomaterials. 2006;27(3):324-334.

13. Jacobs W, Willems PC, van Limbeek J, Bartels R, Pavlov P, Anderson PG, Oner C. Single or double-level anterior interbody fusion techniques for cervical degenerative disc disease. Cochrane Database Syst Rev. 2011;1:CD004958.

14. Hessler C, Boysen K, Regelsberger J, Vettorazzi E, Win- kler D, Westphal M. Patient satisfaction after anterior cervical discectomy and fusion is primarily driven by relieving pain. Clin J Pain. 2012;28(5):398-403.

15. Han SY, Kim HW, Lee CY, Kim HR, Park DH. Standalone cages for anterior cervical fusion: are there no problems? Korean J Spine. 2016;13(1):13-19.

16. Faldini C, Chehrassan M, Miscione MT, Acri F, d'Amato M, Pungetti C, Luciani D, et al. Single-level anterior cervical discectomy and interbody fusion using PEEK anatomical cervical cage and allograft bone. J Orthop Traumatol. 2011;12(4):201-205.

17. Chen Y, Lu G, Wang B, Li L, Kuang L. A comparison of anterior cervical discectomy and fusion (ACDF) using self-locking stand-alone polyetheretherketone (PEEK) cage with ACDF using cage and plate in the treatment of three-level cervical degenerative spondylopathy: a retrospective study with 2-year follow-up. Eur Spine J. 2016;25(7):2255-2262.

18. Liu Y, Wang H, Li X, Chen J, Sun H, Wang G, Yang H, et al. Comparison of a zero-profile anchored spacer (ROI-C) and the polyetheretherketone (PEEK) cages with an anterior plate in anterior cervical discectomy and fusion for multilevel cervical spondylotic myelopathy. Eur Spine J. 2016;25(6):1881-1890.

19. Zhang L, Wang J, Tao Y, Feng X, Yang J, Zhang S. Outcome evaluation of zero-profile implant compared with an anterior plate and cage used in anterior cervical discectomy and fusion: a two-year follow-up study. Turk Neurosurg. 2016;26(3):416-422.

20. Lied B, Roenning PA, Sundseth J, Helseth E. Anterior cervical discectomy with fusion in patients with cervical disc degeneration: a prospective outcome study of 258 patients (181 fused with autologous bone graft and 77 fused with a PEEK cage). BMC Surg. 2010;10:10.

21. MacDermid JC, Walton DM, Avery S, Blanchard A, Etruw E, McAlpine C, Goldsmith CH. Measurement properties of the neck disability index: a systematic review. J Orthop Sports Phys Ther. 2009;39(5):400-417.

22. Trouli MN, Vernon HT, Kakavelakis KN, Antonopoulou MD, Paganas AN, Lionis CD. Translation of the Neck Disability Index and validation of the Greek version in a sample of neck pain patients. BMC Musculoskelet Disord. 2008;9:106.

23. Abbas SF, Spurgas MP, Szewczyk BS, Yim B, Ata A, German JW. A comparison of minimally invasive posterior cervical decompression and open anterior cervical decompression and instrumented fusion in the surgical management of degenerative cervical myelopathy. Neurosurg Focus. 2016;40(6):E7.

24. Burkhardt BW, Brielmaier M, Schwerdtfeger K, Sharif S, Oertel JM. Smith-Robinson procedure with an autologous iliac crest for degenerative cervical disc disease: a 28-year follow-up of 95 patients. World Neurosurg. 2016;92:371-377.

25. Hisey MS, Zigler JE, Jackson R, Nunley PD, Bae HW, Kim KD, Ohnmeiss DD. Prospective, randomized comparison of one-level Mobi-C cervical total disc replacement vs. anterior cervical discectomy and fusion: results at 5-year follow-up. Int J Spine Surg. 2016;10:10. 
26. McAviney J, Schulz D, Bock R, Harrison DE, Holland B. Determining the relationship between cervical lordosis and neck complaints. J Manipulative Physiol Ther. 2005;28(3):187-193.

27. Wu WJ, Jiang LS, Liang Y, Dai LY. Cage subsidence does not, but cervical lordosis improvement does affect the long-term results of anterior cervical fusion with standalone cage for degenerative cervical disc disease: a retrospective study. Eur Spine J. 2012;21(7):1374-1382.

28. Park MS, Kelly MP, Lee DH, Min WK, Rahman RK, Riew KD. Sagittal alignment as a predictor of clinical adjacent segment pathology requiring surgery after anterior cervical arthrodesis. Spine J. 2014;14(7):1228-1234.

29. Hwang SH, Kayanja M, Milks RA, Benzel EC. Biomechanical comparison of adjacent segmental motion after ventral cervical fixation with varying angles of lordosis. Spine J. 2007;7(2):216-221.

30. Machino M, Yukawa Y, Imagama S, Ito K, Katayama Y, Matsumoto T, Inoue T, et al. Age-related and degenerative changes in the osseous anatomy, alignment, and range of motion of the cervical spine: a comparative study of radiographic data from 1016 patients with cervical spondylotic myelopathy and 1230 asymptomatic subjects. Spine (Phila Pa 1976). 2016;41(6):476-482.

31. Chien A, Lai DM, Wang SF, Hsu WL, Cheng CH, Wang
JL. Comparison of cervical kinematics, pain, and functional disability between single- and two-level anterior cervical discectomy and fusion. Spine (Phila $\mathrm{Pa}$ 1976). 2016;41(15):E915-922.

32. Seng C, Tow BP, Siddiqui MA, Srivastava A, Wang L, Yew AK, Yeo W, et al. Surgically treated cervical myelopathy: a functional outcome comparison study between multilevel anterior cervical decompression fusion with instrumentation and posterior laminoplasty. Spine J. 2013;13(7):723-731.

33. Landers MR, Addis KA, Longhurst JK, Vom Steeg BL, Puentedura EJ, Daubs MD. Anterior cervical decompression and fusion on neck range of motion, pain, and function: a prospective analysis. Spine J. 2013;13(11):16501658.

34. Hilibrand AS, Balasubramanian K, Eichenbaum M, Thinnes JH, Daffner S, Berta S, Albert TJ, et al. The effect of anterior cervical fusion on neck motion. Spine (Phila Pa 1976). 2006;31(15):1688-1692.

35. Nordin M, Carragee EJ, Hogg-Johnson S, Weiner SS, Hurwitz EL, Peloso PM, Guzman J, et al. Assessment of neck pain and its associated disorders: results of the Bone and Joint Decade 2000-2010 Task Force on neck pain and its associated disorders. J Manipulative Physiol Ther. 2009;32(2 Suppl):S117-140. 